\title{
Limited but satisfied: Low SES older adults experiences of aging in place
}

\author{
Ginger White \\ Indiana University \\ giwhite@indiana.edu
}

\author{
Tanya Singh \\ Indiana University \\ tasingh@indiana.edu
}

\author{
Kelly Caine \\ Clemson University \\ caine@clemson.edu
}

\author{
Kay Connelly \\ Indiana University \\ connelly@indiana.edu
}

\begin{abstract}
While many aging in place technologies have been explored in the literature, few have focused on low socioeconomic status (SES) populations. Contextual observations $(n=8)$ were used to gain an in-depth view of the daily needs and challenges of low SES older adults and to provide insights into their experiences of health in and around the home. Our findings have implications not only for the kinds of technologies this population could benefit from, but the way in which such technologies are designed to fit into their current lifestyle.
\end{abstract}

Keywords-low SES; urban; rural; aging; aging in place; gerentechnology

\section{INTRODUCTION}

In 2009 there were 39.6 million older adults living in the United States [1]. Many of these older adults live in poverty or are low income [1]. Low socioeconomic status (SES) older adults generally cannot afford to relocate to assisted living facilities or hire formal caregivers. Assisted living services can cost upwards to $\$ 81,030$ annually [2]. To compensate for lack of formal care, informal caregivers are charged with caring for their older loved ones. Caregiving can be burdensome for an already overloaded and sometimes overworked caregiver [3]. Unfortunately, many older adults do not have a readily accessible caregiver within their living environment.

In 2010, 11.3 million older adults age 65 years or older lived alone [1]. Many reside in very rural and urban (inner-city) locations. Older adults living in rural areas usually experience several barriers such as limited transportation, lack of quality health care, and social isolation [4]. Likewise, older adults form urban areas typically experience some type of functional loss due to the deteriorating nature of their environment [5].

To help mitigate caregivers' stress and to help older adults reside in their homes for longer, several aging in place technologies have been created. Unfortunately, many of these research studies fail to explore the needs of low SES older adults. Even fewer explore the potential challenges of older adults residing in urban or rural areas. In this paper we explored the needs of low SES older adults living in rural or urban environments. Contextual observations were used to gain an in-depth view of the daily needs and challenges of low SES urban- and rural-dwelling older adults. Specifically in this paper we provide insights into low SES older adults' experiences of health in and around the home. Additionally, we report on rural and urban older adults' differences in health perception and satisfaction, coping mechanisms, and forced limited choices due to their environment, financial status, and health conditions. Lastly, we discuss how these findings provide various design implications for aging in place technology for this largely unexplored population.

\section{RELATED WORK}

Much work has been done in industry and academia to help combat the growing need of support for aging adults. For example, a variety of assistive technologies such as canes, walkers, and modified toilet seats have been developed to help older adults remain independent in their homes. Although these devices are helpful, many focus on observing one occurrence in the older adults' daily routine. Few if any, allow the older adult to capture information over an extended period. Since many low SES urban- and rural-dwelling older adults experience a lack of quality healthcare [6] or functional loss [5] as they age, not having consistent monitoring can result in earlier relocation to a costly assisted living facility.

There are other services that allow the constant monitoring of older adults. An example commercial product is QuietCare - a system that allows caregivers to consistently monitor older adults' daily activity levels through motion sensors positioned around the home [7]. Aside from commercial products and devices, older adults' family members can employ in-home caregivers or companions. These persons provide assistance with routine activities throughout the day (e.g. cooking, cleaning, bathing, or running errands) [2]. If this service is not desirable, family members also have the option to relocate their older loved ones to assistive living facilities or nursing homes. Assisted living services can cost upwards to $\$ 3,300$ monthly, and nursing homes can cost upwards to $\$ 220$ per day [2]. With this being said, many of these services are inaccessible to low SES older adults. Although they provide consistent monitoring of various health conditions, many of these services can be costly and few are totally covered by health insurance or Medicaid [8] - a major limitation for low SES older adults.

To decrease the chance of relocating to nursing homes or senior housing, several researchers have focused their studies on developing aging in place technologies to assist older adults in their daily activities and help ease the stress of caregivers. Some researchers chose to develop aging in place devices tailored to the needs of high SES older adults (e.g., [9, 10]). However, many aging in place devices were developed to help the general older adult population despite income level [11,12]. Although these projects did not specifically target high SES older adults, most aging in place devices were typically evaluated with older adults who were high SES, had available caregivers, lived in environments designed for seniors, or had 
the necessary technological infrastructure to sustain the aging in place devices.

Many current aging in place designs focus on connecting older adults to three populations: local caregivers, remote family and friends, and peers. An example technology that connects older adults to a local caregiver includes the CareNet, monitoring support system that captures older adults' daily activities and displays health trends [13]. The family message board is an example technology that has the ability to help older adults communicate with family members who are not living in the same geographical location, through the use of virtual "sticky notes" [14]. Lastly, an example technology that connects older adults with their peers is the markerClock, a clock that displays markers at specific times to show older adults' daily movement [15]. This type of technology requires older adults to have a peer network that are located in close proximity of one another. The aforementioned technologies are simple examples that focus on connecting older adults. There have been however, many aging in place devices that also highlight these three areas. All of these technologies are novel in design; however most have been developed with the understanding that older adults have certain available resources such as, formal caregivers, or established peer networks; resources that are more prevalent among high-SES older adults living in suburban residential neighborhoods. Whether intentional or unintentional, all the aforementioned aging in place projects failed to focus on understanding the needs of low SES urban- or rural-dwelling older adults.

\section{METHOD}

Eligibility for this study required that participants be age 70 or older, live alone in an urban or rural environment, and have a low SES (as determined by the US Census bureau). In 2012, low SES was calculated at $200 \%$ of the federal poverty level or an annual income less than $\$ 20,000$ [16]. Participants' demographics and technology use were collected using two separate questionnaires which are described in detail in the following section. Eight-hour contextual observations were conducted at each of the participants' homes to collect information on older adults' daily routines, health practices, home technology use and to discover the types of unmet needs that may be present.

\section{A. Participants}

We collected a total of 72 hours of data from 8 participants. This sample size is double the sample size of similar in depth, exploratory, time-intensive, face-to-face peer-reviewed published studies $(n<4$ in [13]). Participants were 8 female older adults between the ages of 69 (one participant was a few months shy of 70$)$ and $86(\mathrm{M}=77.25, \mathrm{SD}=5.78)$. Participants resided in urban $(n=4)$ and rural $(n=4)$ environments. They lived alone in an apartment $(n=5)$, single-family house $(n=2)$, or mobile home $(n=1)$, were retired, and had an income of less than $\$ 20,000$ a year (Table I). Although participants reported having health conditions such as cancer, diabetes, and stroke (Table II), participants were still high- functioning, independent older adults. All participants $(\mathrm{N}=8)$ could perform daily activities such as cooking, cleaning, engaging in hobbies, and socializing without any assistance.
TABLE I. PARTCIPANT DEMOGRAPHICS

\begin{tabular}{|c|c|c|c|}
\hline Variable & $\begin{array}{c}\text { Urban } \\
\text { Participants } \\
(\mathrm{N}=4)\end{array}$ & $\begin{array}{c}\text { Rural } \\
\text { Participants } \\
(\mathrm{N}=4)\end{array}$ & $\begin{array}{c}\text { Total } \\
\text { Participants } \\
(\mathrm{N}=8)\end{array}$ \\
\hline Age & $77(\mathrm{SD}=1.15)$ & $77.5(\mathrm{SD}=8.74)$ & $77.25(\mathrm{SD}=5.78)$ \\
\hline \multicolumn{4}{|c|}{ Marital Status } \\
\hline Divorced & 1 & 1 & 2 \\
\hline Widowed & 3 & 3 & 6 \\
\hline \multicolumn{4}{|c|}{ Occupational Status } \\
\hline Retired & 4 & 4 & 8 \\
\hline \multicolumn{4}{|c|}{ Housing } \\
\hline House & 1 & 1 & 2 \\
\hline Apartment & 3 & 2 & 5 \\
\hline Mobile Home & 0 & 1 & 1 \\
\hline
\end{tabular}

\section{B. Procedure}

The entire study took place over 8 consecutive hours in the home of each older adult and included the following sections (specific materials described in detail in the materials section below): informed consent, demographic, health, and technology questionnaire, semi-structured interview, and contextual observation. First, researchers explained the purpose of the study and obtained consent from participants. Next, participants were asked to complete a series of questionnaires to provide information about participant characteristics including health status and the types of technologies participants used. After the questionnaires were completed, a semi-structured interview was conducted with each participant.

The interview consisted of questions regarding participants' support system and daily routines and challenges while living at home. The interview lasted approximately 45 minutes, was audio recorded and later transcribed verbatim for analysis. The interviewer also took field notes during each interview.

\section{TABLE II. PARTCIPANT HEALTH CONDITIONS}

Note: $\bullet$ : participant has had health condition in their lifetime, $\mathbf{D}$ : participant currently has health condition, $\bigcirc$ : participant has never had health condition.

\begin{tabular}{|c|c|c|c|c|c|c|c|c|}
\hline & \multicolumn{4}{|c|}{ Urban Participants } & \multicolumn{4}{|c|}{ Rural Participants } \\
\hline $\begin{array}{l}\text { Health } \\
\text { Conditions }\end{array}$ & $P 1$ & $P 2$ & $P 3$ & $P 4$ & $P 5$ & P6 & $P 7$ & P8 \\
\hline Arthritis & D & D & O & 0 & 0 & 0 & D & 0 \\
\hline $\begin{array}{l}\text { Asthma/ } \\
\text { Bronchitis }\end{array}$ & 0 & - & O & 0 & 0 & 0 & 0 & 0 \\
\hline Cancer & - & 0 & 0 & 0 & 0 & - & - & 0 \\
\hline Diabetes & 0 & 0 & D & D & 0 & 0 & D & $\mathrm{O}$ \\
\hline Epilepsy & 0 & 0 & 0 & O & 0 & 0 & 0 & $\mathrm{O}$ \\
\hline Heart Disease & D & D & 0 & 0 & 0 & - & 0 & D \\
\hline $\begin{array}{l}\text { Hearing } \\
\text { Impairment }\end{array}$ & $\bigcirc$ & O & 0 & ○ & D & D & O & 0 \\
\hline Hypertension & $\mathbf{D}$ & $\mathrm{O}$ & D & D & 0 & D & D & $\mathrm{O}$ \\
\hline Stroke & 0 & D & - & 0 & 0 & - & 0 & 0 \\
\hline $\begin{array}{l}\text { Vision } \\
\text { Impairment }\end{array}$ & 0 & 0 & D & D & 0 & 0 & - & D \\
\hline
\end{tabular}


After the interview was complete, participants were informed that the formal portion of the interview was finished and were asked to go about their daily routine. The researcher then began the contextual observation. The contextual observation consisted of the researcher observing participants' routines for the entire day, while occasionally asking participants questions for more details. Participants were instructed to behave as they would on any normal day so the researcher could gain an understanding of participants' daily needs and challenges. As participants moved about their home over the course of the day, the researcher would ask questions about how they spent time in that room and about specific home artifacts with which they were interacting. The researcher documented the home using photographs.

At the conclusion of the study, participants were debriefed, thanked for their participation, and offered an additional opportunity to ask any remaining questions. Participants were remunerated $\$ 80$ for their time.

\section{Materials}

Demographic Questionnaire: The demographic questionnaire contained questions pertaining to participants' age, gender, race, occupation, annual income, retirement year, pre-retirement occupation, and primary transportation.

Health Questionnaire: The health questionnaire contained questions pertaining to current and past medical conditions as well as perceptions of overall health, health when compared to peers, and satisfaction with overall health. For health satisfaction, perception and comparison, a 5-point Likert scale was used.

Semi-structured Interview: The semi-structured interview inquired about participants' daily routines and challenges when living at home. More specifically, the interviews contained questions relating to services, agencies, and support systems available to older adults in their communities.

Contextual Observations: For purposes of discussion, we describe the contextual observation in two parts: structured and unstructured. Structured observations were facilitated using a series of pre-existing and custom worksheets designed to gather information about the external condition and various features in a participant's area. For example, public and commercial resources located within a one to two mile radius and neighborhood features were captured using a modified The Rural Active Living Assessment (RALA) tool [17]. The social environment and neighborhood condition were captured using the audit tool checklist [18]. Transportation options were collected using a custom tool that combined questions from the PIN3 neighborhood audit tool [19] and the active neighborhood checklist [20], both of which we adapted to capture public transportation options with a custom transportation checklist. The modified Home And Community Environment (HACE) instrument [21] was used to collect information about assistive technologies and an adapted assessment of life habit tool [22] was used to collect information about daily living activities. We also generated custom tools to collect information about emergency response options, the home living environment (including home size and style) and technologies in the home.
Unstructured observations were observations the researcher made that were not based on a priori identified areas of interest. Rather, these were emergent based on the characteristics of the participants and the qualities of the home environment.

\section{Data Analysis}

All interviews were both audio recorded and documented with notes from the research team. Interviews were transcribed verbatim, totaling 429 pages of transcripts. Transcripts were coded for emergent themes using the following process. First, research team members $(n=4)$ independently read through the transcripts and discussed as a team. Second, the team iterated on emergent themes until they identified the following seven themes: forced limited choices, health satisfaction, coping mechanisms, asserted freedom, needs/help, boredom/ loneliness, and relationship with caregiver. Third, the transcripts were then segmented and coded, resulting in 287 coded segments. Fourth, the team read through all of the coded segments and iterated on sub-codes within each high-level code. Lastly, all segments were coded down to the level of the sub-code.

\section{RESULTS}

Because of the broad scope of our interviews, observations and subsequently the vast amount of data we collected, it is impossible to report all the results in one paper. Therefore, here we focus on the three themes centered on health at home: health satisfaction, coping mechanisms, and forced limited choices. A total of 188 segments were identified as being one of these three themes ( $65.51 \%$ of all coded segments). For each theme, we present data from related questionnaires (e.g. health satisfaction ratings), structured observations (e.g. public resources) and interviews. Qualitative data are represented in two ways: a table summarizing the raw number of segments identified for each code, and representative quotes to illustrate the themes.

\section{A. Health Satisfaction}

To ground the results from our sample, we compare our participants to participants from a larger survey study conducted with 461 older adults, ages $60-91$. The goal of this survey study was to understand factors predicting technology use among different age groups [23]. For comparison purposes, we adopted the same demographic and health survey as used in the large survey study. The comparison of our rural and urban participants to this larger sample [23] is presented in Table III.

In general, our urban participants rated their comparison of their health to their peers, health satisfaction and health hindrance similarly to the larger population. Our urban participants rated their personal health less positively to their peers than the representative sample. In contrast, our rural participants rated their personal health, comparison of their health to their peers, health satisfaction and health hindrance less well as compared to both our urban participants and the representative sample. While our sample size is too small to draw definitive conclusions about low SES urban and rural dwelling older adults in general, it does provide a lens with which to interpret our specific participants. 
Within the larger theme of health satisfaction, there were four sub-codes: comparison to peers, health limitation, health perspective (positive and negative), and independence (Table IV). We discuss each of these sub-codes below.

Comparison to Peers: Generally both urban and rural older adults perceived their health was good when compared to their peers $(3 / 4$ and $2 / 4$, respectively, rated their health as good or better as compared to their peers) (Table III). During the interviews and observations, two urban and one rural participant spontaneously compared themselves to their peers when describing their health or health limitations. Their comparison tended to be positive, focusing on how much more they could do compared to other people their age:

"My health I think is better than most of them down there at the senior center. They don't have too many down there my age." - Rural P7

"I know a lady, she's the same age that I am. She sit around the house, doing nothing. I don't understand it." - Urban P5

Health Limitation: In the questionnaire, three urban and two rural participants reported their health seldom hindered daily activities (Table III). Yet throughout the contextual observations, a majority of both urban $(n=3)$ and rural $(n=3)$ participants discussed having health limitations (Table IV). Both rural and urban participants discussed limitations as a result of a specific health condition:

"My stroke was on my right side, and they wouldn't let me feed myself with my left hand. I had to do everything with my right hand." - Rural P7

"I have a little nervous in this hand so it's going to shake if I write so I know I'm not going to write too much longer." - Urban P3

In addition, they discussed general limitations due to aging: "After I sew, I seem like I just can't see. My eyes gets tired, so then I have to quit." -Rural P7

\section{TABLE III. PARTCIPANT HEALTH RATING}

a. Note: 'Older adults (age 60-91) personal health, comparable health, health satisfaction, and health hindrance data is drawn from a larger study of 461 older adults. [23] ${ }^{2}$ : good $+=$ participant ratings include good, very good, and excellent ${ }^{3}$ : somewhat satisfied $+=$ participant ratings include somewhat satisfied and extremely satisfied, ${ }^{4}$ : participant ratings include seldom and never

\begin{tabular}{|l|l|l|l|}
\hline & \multicolumn{1}{|c|}{$\begin{array}{c}\text { Urban } \\
\text { Participants } \\
(\mathbf{N}=\mathbf{4})\end{array}$} & $\begin{array}{c}\text { Rural } \\
\text { Participants } \\
(\mathbf{N}=\mathbf{4})\end{array}$ & $\begin{array}{c}\text { Older Adults } \\
\text { age 60-91 } \\
(\mathbf{N}=\mathbf{4 6 1})^{1}\end{array}$ \\
\hline Personal Health $^{2}$ & $50 \%$ good + & $25 \%$ good + & $73 \%$ good + \\
\hline $\begin{array}{l}\text { Compared } \\
\text { Health }\end{array}$ & $75 \%$ good + & $50 \%$ good + & $65 \%$ good + \\
\hline $\begin{array}{l}\text { Health } \\
\text { Satisfaction }\end{array}$ & $\begin{array}{l}\text { 3 } \\
\text { satisfied }+\end{array}$ & $\begin{array}{l}25 \% \text { somewhat } \\
\text { satisfied }+\end{array}$ & $\begin{array}{l}80 \% \\
\text { somewhat } \\
\text { satisfied }+\end{array}$ \\
\hline $\begin{array}{l}\text { Health } \\
\text { Hindrance }\end{array}$ & $75 \%$ seldom - & $50 \%$ seldom - & $70 \%$ seldom - \\
\hline
\end{tabular}

TABLE IV. HEALTH SATISFACTION

\begin{tabular}{|l|l|l|l|l|}
\hline & \multicolumn{2}{|c|}{ Urban } & \multicolumn{2}{c|}{ Rural } \\
\cline { 2 - 5 } & $\begin{array}{l}\text { Participants } \\
(\mathbf{N = 4 )}\end{array}$ & $\begin{array}{c}\text { Total times } \\
\text { mentioned by } \\
\text { participant }\end{array}$ & $\begin{array}{l}\text { Participan } \\
\text { ts (N=4) }\end{array}$ & $\begin{array}{c}\text { Total times } \\
\text { mentioned by } \\
\text { participant }\end{array}$ \\
\hline $\begin{array}{l}\text { Comparison to } \\
\text { Peers }\end{array}$ & 2 & 5 & 1 & 2 \\
\hline $\begin{array}{l}\text { Health } \\
\text { Limitation }\end{array}$ & 3 & 6 & 3 & 25 \\
\hline $\begin{array}{l}\text { Health } \\
\text { Perspective }\end{array}$ & 3 & $8(4-$ and4+) & 4 & $7(2$-and 5+) \\
\hline Independence & 3 & 4 & 1 & 3 \\
\hline
\end{tabular}

Several participants specifically mentioned getting tired quickly and taking longer to do things around the house than when they were younger:

"When I come home, I'm tired. I need to lay down or sit down, whatever." - Urban P5

"One day I dusted the ceiling, cleaned my fans, and dusted off my wall paper and my pictures. That took me all day, because I work a while, and then I have to sit down a while. - Rural P7

While urban and rural participants reported similar health limitations, rural participants discussed their limitations more frequently and in-depth than their urban counterparts (Table IV).

Health perspective: While nearly $75 \%$ of the representative sample of older adults rate their personal health as good or better, only $50 \%(2 / 4)$ or our urban participants and $25 \%(1 / 4)$ of our rural participants rated their health as good or better, which is somewhat surprising given the high level of independence of all participants.

All rural and three urban participants specifically discussed their health perspective during the interviews and observations (Table IV). The urban participants equally discussed positive and negative aspects of their health:

"It's a blessing to reach an age like this." - Urban P4

"I know my walking skill is not like it used to be."

-Urban P1

While the rural participants tended to focus more on the positive aspects of their health:

"Well I tell you, my health is very good. I will put that. I'm lucky." - Rural P6

Independence: All participants were high-functioning older adults and could perform daily activities without assistance. During the interviews and observations, a majority of urban participants $(n=3)$ discussed feeling independent; whereas only one rural participant did. Participants tended to focus on taking care of themselves for as long as they could:

"I think I can really take care of myself for a few more years. " - Urban P1

"As long as I can drive, I'll drive. I think I get along pretty good with driving." - Rural P7 


\section{B. Coping Mechanism}

The research team defined coping mechanism as a way of coping with a personal or environmental issue such as one's personal health, financial status, home conditions, relationships, and exterior environment. The major sub-codes that emerged from coping mechanisms included financial, home and health (Table V). In addition, there were a few miscellaneous coping mechanisms that occurred with a single participant.

Financial: Given that our population was low SES, it was not surprising that participants mentioned ways in which they coped with their limited financial resources. One urban participant (P5) discussed coping by finding other opportunities to make money and obtain food (collect and recycle cans, eat at the senior center and get food from community food pantries):

"They give food away up there, I go up there every

Saturday, go to collect their food." - Urban P5

Coping strategies discussed by rural participants included maintaining health insurance to reduce medical expenses, personally completing all home repairs, and driving instead of asking for transportation to save money for gas:

"I could get somebody to come and get me but that's a lot of gas... I'll drive." - Rural P8

Home: One urban participant discussed coping with her previous home conditions by opting to move into her current dwelling that is more suited for senior living. A majority of rural participants $(n=3)$ discussed coping with their current home conditions. Some coping mechanisms include adopting assistive home technologies and swapping rooms:

"I got so I couldn't do the steps, so they brought my craft down her and put it in there." - Rural P7

Health: Urban and rural participants reported that their health seldom interfered with completing daily activities (Table IV). However, during the interviews, all urban participants $(n=4)$ and a majority of rural participants $(n=3)$ discussed coping with various health issues. Some coping mechanisms discussed by urban participants included: adjusting clothing materials and styles, driving and walking shorter distances, and thoroughly planning daily routines.

One urban participant discussed taking showers because she fears falling when getting up from a bath:

"I'm afraid to take a bath because I'm afraid I can't get up. I usually just take a shower." - Urban P5

TABLE V. COPING MECHANISMS

\begin{tabular}{|l|l|l|l|l|}
\hline & \multicolumn{2}{|c|}{ Urban } & \multicolumn{2}{c|}{ Rural } \\
\cline { 2 - 5 } & $\begin{array}{c}\text { Participants } \\
(\boldsymbol{N}=4)\end{array}$ & $\begin{array}{c}\text { Total times } \\
\text { mentioned } \\
\text { by } \\
\text { participant }\end{array}$ & $\begin{array}{l}\text { Participants } \\
(\boldsymbol{N}=4)\end{array}$ & $\begin{array}{l}\text { Total times } \\
\text { mentioned } \\
\text { by } \\
\text { participant }\end{array}$ \\
\hline Environmental & 0 & 0 & 1 & 1 \\
\hline Financial & 1 & 2 & 2 & 5 \\
\hline Home & 1 & 3 & 3 & 6 \\
\hline Health & 4 & 13 & 3 & 20 \\
\hline
\end{tabular}

Coping mechanisms discussed by rural participants included: taking fewer showers, incorporating resting periods throughout daily activities, spreading out daily activities, adjusting the amount of daily movement, and decreasing amount of driving or sharing driving responsibilities.

One rural participant explained that she would share the driving responsibilities with peers when she needs to attend a doctor's appointment.

"Bettie Bird will drive me; take my car and drive it, and then we have Anita and Mary Cook, and there'll be four of us going." - Rural P7

The same rural participant explained that she needed to rest shortly after doing daily chores:

"I work about five or ten minutes. Now, I got to sit down for five to ten." - Rural P7

Miscellaneous: Other coping strategies mentioned by fewer participants included coping with living alone, unsafe road conditions and transportation arrangements. For example, to be able to ride the free shuttle bus to the grocery store each week, six or more older adults have to agree to go. If less than six sign-up then the shuttle will not run. To combat this, one urban participant takes the public bus.

"That's how I do my grocery shopping, on the bus here... It has to be six or more... I get <public bus name $>$... I go on my own...-Urban P1

\section{Forced Limited Choices}

The research team defined forced limited choices as the decisions individuals made due to constraints on which they have no control. Three sub-codes emerged in the forced limited choices theme: environmental, financial and health.

Environmental: All rural participants discussed being forced to utilize certain resources due to their environment (Table VI). Some of these limited choices include small food market, one community clinic, unkempt roads, and lack of technology infrastructure. As shown in Table VII, rural participants do in fact have fewer public and neighborhood resources than urban participants.

One rural participant in particular discussed having to take a longer route to the store because of the condition of the shorter roads.

"I'd just rather go to better roads. It takes a little longer, but it's okay." -Rural P7

TABLE VI. FORCED LIMITED CHOICES

\begin{tabular}{|l|l|l|l|l|}
\hline \multirow{2}{*}{} & \multicolumn{2}{|c|}{ Urban } & \multicolumn{2}{c|}{ Rural } \\
\cline { 2 - 5 } & $\begin{array}{c}\text { Participants } \\
(\mathbf{N = 4 )}\end{array}$ & $\begin{array}{c}\text { Total times } \\
\text { mentioned } \\
\text { by } \\
\text { participant }\end{array}$ & $\begin{array}{l}\text { Participants } \\
(\boldsymbol{N}=4)\end{array}$ & $\begin{array}{l}\text { Total times } \\
\text { mentioned } \\
\text { by } \\
\text { participant }\end{array}$ \\
\hline Environmental & 0 & 0 & 4 & 19 \\
\hline Financial & 2 & 9 & 4 & 14 \\
\hline Health & 2 & 2 & 3 & 8 \\
\hline
\end{tabular}


TABLE VII. PUBLIC RESOURCES

\begin{tabular}{|c|c|c|c|c|c|c|}
\hline & $\begin{array}{c}\text { Public } \\
\text { bus } \\
\text { transit }\end{array}$ & Library & $\begin{array}{c}\text { Post } \\
\text { office }\end{array}$ & Hospital & $\begin{array}{c}\text { Food } \\
\text { Market }\end{array}$ & $\begin{array}{c}\text { Police/Fire } \\
\text { Station }\end{array}$ \\
\hline Urban & 3 & 4 & 4 & 4 & 4 & 4 \\
\hline Rural & 0 & 0 & 2 & 0 & 1 & 2 \\
\hline
\end{tabular}

Financial: All of the rural participants and half of the urban participants discussed being forced to utilize certain resources due to financial constraints. Both urban and rural participants felt they were forced to utilize unhealthy and unpleasant meal programs because of financial constraints:

“... everything is starch, starch, starch, starch, starch, and I was gaining weight. I said, this ain't for me...the meals on wheel are not healthy." -Rural P7

Health: Half of the urban participants discussed being forced to utilize certain things because of their health. In particular, urban participants discussed utilizing showers instead of baths, and relocating to senior housing instead of residing in previous homes because of health issues. An urban participant discussed that she had to move to her current home that is more suited for senior living because she had a stroke.

\section{"I had a stroke and that is the reason I am here."}

\section{-Urban P3}

A majority of rural participants $(n=3)$ also discussed being forced to utilize certain resources due to health issues. Rural participants discussed having different limited choices due to health issues, some include: certain furniture height to insure one can get in and out of the chair, certain food types because of food allergies, and certain transportation options due to motion sickness.

To ensure that she can get in and out of chairs, one rural participant altered the legs of her couch. Another rural participant described how she could no longer walk outside because of the uneven surface and her bad knees:

“With my knees as bad as they were, I couldn't walk on this ground. It's too unlevel, and it's too hard to walk on." - Rural P8

\section{DISCUSSION}

In the previous section we described the results from a series of in depth, contextual interviews with 8 low SES older adults. Based on these results we identified three high level themes related to aging in place for low-SES older adults (health satisfaction, coping mechanisms and forced limited choices) that emerged from our observations, conversations and interactions with these older adults. We found that participants were generally satisfied with their health, especially in comparison to their peers, even though they experienced some limitations due to their health. In addition, we found that older adults developed varied and specific strategies of coping with their personal health, financial status, home condition and exterior environment. Finally, we found that despite having these coping mechanisms, participants still dealt with forced limited choices stemming from environmental, financial and health limitations.
In the following section we discuss two potential promising areas for designing pervasive aging in place technologies that support low SES older adults, similar to those in our study.

\section{Contextualize health with peers:}

One possible area to improve design is in shifting the focus of health monitoring from inadvertently highlighting decline to a purposeful emphasis on positive comparisons with peers. Many existing health monitoring devices that are designed to display older adults' health information to a local caregiver [13], remote family member $[10,11,14]$ or peer [15], promote monitoring and caregiving by comparing the older adults' daily activities to historical, personalized norms [see Fig. 1]. The goal of these devices is to allow the older adult and caregiver to monitor health over time and thus increase self-motivation to take action on their health and/or notify a caregiver if a significant decline occurs. However, this strategy may be demotivating for a population whose health will eventually decline.

The older adults in our study, instead of focusing on decline, contextualized their health in terms of how they were doing in comparison to their peers (e.g., section IV health satisfaction). This insight reveals an opportunity to create aging in place technologies that are more in line with how older adults see themselves by allowing older adults to compare their positive health attributes with those of their peers. Enabling older adults in this way may encourage them to focus on attributes that are still flourishing, as opposed to highlighting eventual declines in their overall health due to age.

This move from a comparison exclusively with their younger selves to a comparison with peers may be a way to encourage them to retain a positive outlook on their overall health, even in the face of health declines.

Older adults in our study rarely, if ever, compared themselves to their peers in a negative way (i.e., saying how they could not do something compared to their peers), but instead, used comparisons to focus on the positive aspects of their health and situation.

Since older adults are likely to have poorer health and abilities in some areas than their peers, any technology designed for the purpose of contextualizing health needs to be adaptable enough to emphasize positive comparisons, or encourage changes where there is a realistic chance of improvement, instead of highlighting issues that the older adult is unlikely to be able to control.

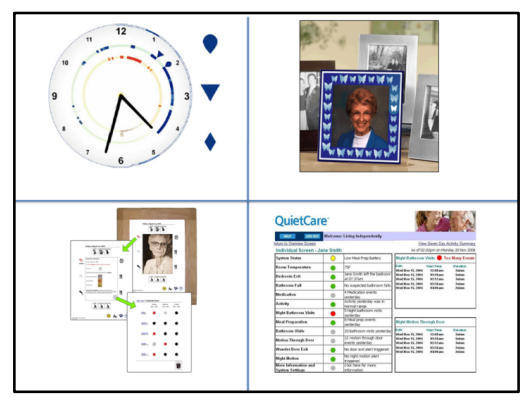

Fig. 1. Daily personlized norms (Clockwise, starting from top left) markerClock[15], digital family portrait [11], quietCare [7], careNet[13]. 
Differentiating between health and lifestyle changes that can occur and those that are unlikely is something we find absent in the existing design literature.

In our design work in this area we plan to investigate interaction patterns to contextualize health with peers. We note two immediate challenges to designing these systems. The first challenge is to gather enough health data for meaningful comparisons. One approach would be to gather data from an existing representative sample of older adults for use as comparison. However, low SES older adults may not favorably compare to the representative sample because they generally have worse health outcomes than their higher SES peers [5, 24]. Therefore, an alternative solution would be to gather health data from local low SES peer networks where health disparities within the network would likely be lower. This suggests that interventions that target the community as the level of deployment as opposed to the individual may be more successful. Once we have the data from the appropriate group, a second challenge is data analyses. This analysis is tricky for two reasons: 1) extracting positive health comparisons on an individual basis and 2) distinguishing between activities and context that the older adult may be able to change and things they can't change. These challenges reinforce the need for focused further research in this area.

\section{Utilize peer networks to cope with forced limited choices:}

The contextual observations revealed that urban and rural older adults felt they were forced to utilize certain resources due to their environment, finances, and/or health conditions. For example, financial constraints led participants to eat lowcost, unhealthy and tasteless meals because they could not afford otherwise. When discussing environmental limitations, both urban and rural older adults discussed having to go grocery shopping at inconvenient times because they had limited transportation within their environment. In addition, rural older adults were orced to utilize hospitals that are far away because none existed within their environment.

However, we observed that not all participants experienced limited choices, or were better equipped to handle these limitations. For example, some of the urban and rural older adults discussed finding free resources that allowed them to have a variety of meals to choose from. Specifically, recall that one urban participant visited a local food market to receive the free giveaways each week. A rural participant also often received free food from the local churches:

\section{"They [church] just voluntarily bring it [food]." \\ -Rural P9}

Unfortunately, not all older adults in our study knew about these available services within their community. Thus there is an opportunity to design technologies that distribute information about available resources. One way specific community based information could successfully distributed in other settings is via the use of peer networks. Specifically, the technology could act as a forum to help older adults collaborate and dispense their knowledge of non-widely known resources. Similar to Grimes' work helping people share stories about how to eat healthy in a low SES, urban environment [25], older adults could help each other find reliable resources. To ease the stress of financial constraints and to cope with environmental limitations, technology could help low SES urban and rural older adults use their peer networks to find low-cost or free services and resources located within their area. The technology could serve to create a trusted environment of older adults and caregivers who facilitate discussion and sharing.

In terms of environmental constraints, the same type of technology could help older adults coordinate transportation to these resources. Many of the rural older adults reported having their own personal vehicle; however, some discussed having limited driving capabilities because of health issues. In particular, some participants reported that they could not drive far because they would get tired. To help counter this health limitation, technology could assist in organizing carpools. The carpools would have several benefits; 1 ) older adults can take turns driving so they would not tire easily, 2) they each can pitch in on the cost of gas, easing the financial burden of each older adult, and 3) they can utilize resources and services that are located outside of their immediate environment.

Similarly, many urban older adults utilized a free shuttle service to go to local places such as grocery stores, but the shuttle only ran if enough people signed up for it. Participants expressed frustration at not knowing if the shuttle "would make". A system that helps older adults coordinate amongst themselves can relieve this frustration by empowering them to be proactive in booking the shuttle.

In our design work, we are developing systems that facilitate community information sharing and complex coordination tasks such as those described above. The system is community driven meaning that the older adults themselves request, provide, consume and act on the information. This is in contrast to most existing systems that support caregivers in assisting older adults in daily tasks.

\section{Summary:}

We identified and described two promising areas for novel pervasive health technologies to support aging in place in low SES communities. We discussed the notion of supporting older adults in comparing the positive attributes of their health with that of their peers in contrast to existing systems that compare to individual historical data. We also discussed the idea of having older adults distribute information regarding available resources in the community or local area. Lastly we proposed that technology could help with complex coordination tasks amongst older adults such as transportation facilitation.

\section{Limitations:}

We acknowledge that our sample size is small $(n=8)$, as is the goal of many exploratory studies of an under theorized area, our goal was to contribute uniquely to existing literature on a largely unexplored population. Our strategy of completing in-depth assessments and spending many hours with a small number of participants, yielded in depth insights about the needs, barriers and opportunities for designing for a largely unexplored population, rather than definitive conclusions about how such designs might affect a population. Findings such as this contribute to the growing literature on pervasive technologies to support aging in place. 


\section{CONCLUSION}

In this paper we presented an in depth exploration of aging in place experiences of an understudied group: rural and urban dwelling low SES older adults. Based on a comparison of the older adults in our sample to a representative sample of older adults, as well as an in depth qualitative exploration of health, home, limitations, and coping mechanisms, we presented results that suggest that both rural and urban low SES older adults are generally satisfied with the health circumstances afforded by their current home, even while these circumstances are limiting. Finally, we explored design opportunities that may lessen many of the limitations experienced by this group while also carefully considering how we might prevent designs that could undermine older adults' satisfaction with their health at home.

\section{ACKNOWLEDGEMENT}

This material is based upon work supported by the National Science Foundation under award number 1117860. Any opinions, findings, and conclusions or recommendations expressed in this presentation are those of the author(s) and do not necessarily reflect the views of the National Science Foundation. We would also like to thank the Center for Law, Ethics and Applied Research in Health Information, the School of Informatics and Computing, Matthew Francisco and all of the participants for their help with this study.

\section{REFERENCES}

[1] Department of Health \& Human Services "A profile of older Americans:2011".Retrieved from http://www.aoa.gov/AoARoot/Aging_Statistics/Profile/2011/docs/2011p rofile.pdf 2011

[2] Genworth (2012) "Genworth 2012 cost of care survey". Retrieved from https://www.genworth.com/dam/Americas/US/PDFs/Consumer/corporat e/coc_12.pdf. 2012

[3] National Alliance for Caregiving. "Caregiving statistics: statistics on family caregivers and family caregiving". Retrieved from http://www.thefamilycaregiver.org/who_are_family_caregivers/care_giv ing_statstics.cfm\#2. 2009

[4] R.T Goins, K.A. Williams, et al. "Perceived barriers to health care access among rural older adults: a qualitative study." The Journal of Rural Health, vol. 21, pp.206-213, 2005.

[5] J. L. Balfour,G. A. Kaplan "Neighborhood environment and loss of physical function in older adults: evidence from the alameda county study". American Journal of Epidemiology, vol. 155, pp.507-515, 2002.

[6] T. Arcury, W. Gesler, J. Preisser, et al. "The effects of geography and spatial behavior on health care utlization among the residents of a rural region" Health Services Research vol. 40,1, 2005.

[7] "QuietCare systems by careinnovations" Retrieved from http://www.careinnovations.com/products/quietcare-assisted-livingtechnology
[8] M. Kitchener, T. Ng, H.Y. Lee, et al. "Assistive technology in medicaid home-and community-based waiver programs." The Gerentologist, vol. 48, pp181-189, 2008,

[9] L. Lorenzen-Huber, M. Boutain, et al. "Privacy, independence, and relationships: older adults' perceptions of home-based ubiquitous technologies". Aging International. (in press) 2011.

[10] K. E. Caine, C. Y. Zimmerman, et.al. "DigiSwitch: design and evaluation of a device for older adults to preserve privacy while monitoring health at home". Proc. of the ACM SIG on IHI. 2010.

[11] E. D. Mynatt, J. Rowan, et al. "Digital family portraits: supporting peace of mind for extended family members." Proc. of the SIGCHI of CHI 2001.

[12] M. L. Lee, A. K. Dey "Embedded assessment of aging adults" Proceedings of Pervasive Health. 2010.

[13] S. Consolvo, P. Roessler, B. Shelton. "The CareNet display: lessons learned from an in home evaluation of an ambient display." Conference on Ubiquitous Computing, pp. 1-17, 2004.

[14] H. Browne, B. Bederson, et al."Designing an interactive message board as a technology probe for family communication." HCIL, pp. 2001-20, 2009.

[15] R. Yann and W. Mackay, "PeerCare: supporting awareness of rhythms and routines for better aging in place," Journal of computer supported collaborative work, vol.19, 1, 2010.

[16] U.S Census Bereau "Poverty thresholds by size of family and number of chidren".Retrieved from https://www.census.gov/hhes/www/poverty/data/threshld/index.html. 2012

[17] A. Yousefian, Hennessy E., et al. "Development of the rural active living assessment tools: measururing rural environments." Preventative Medicine, 2010.

[18] R. Brownson, L. Ramirez, et al. "Analytic audit tool and checklist audit tool." Retrieved from http://www.activelivingresearch.org/node/10616

[19] K. R. Evenson et al. "Assessing urban and rural neighborhood characteristics using audit and GIS data: derivation and reliability of constructs." International journal of Behavioral Nutrition and phsyical activity, 2009.

[20] "Active neighborhood checklist." Retrived from http://activeliving.org/node/681

[21] J. Keysor, A. Jette, S. Haley, "Development of the home and community environment (HACE) instrument. Journal of rehabilitation medicine, vol.37, 1, pp 37-44, 2005.

[22] N. Laval, F. Patrick, V. Claude. "The life-H assessment of the quality of social participation." Technology and disability, vol. 14, 3, pp. 113-118, 2002.

[23] S. Czaja, N. Charness, A. Fisk and C. Hertzog, et al. "Factors Predicting the Use of Technology: Findings From the Center for Research and Education on Aging and Technology Enhancement (CREATE)," Journal of psychol aging, 2006.

[24] J. Van Nostrand. (2003). "Assisted living in rural america: A national survey." "Atrieved from http://www.srph.tamhsc.edu/centers/srhrc/PDF/ruralalfpdf.pdf

[25] A. Grimes, M. Bednar, J.D. Bolter, et al. "EatWell: Sharing NutritionRelated Memories in a Low Income Community." CSCW '08, 2008. 